\title{
IMPLEMENTATION OF THE METHODS OF IDENTIFICATION OF STATIC CONTROL OBJECTS
}

\author{
Sergey G. Pachkin and Roman V. Kotlyarov*
}

Kemerovo Institute of Food Science and Technology (University), Stroiteley blvd. 47, Kemerovo, 650056, Russian Federation

Received November 24, 2017;

* e-mail: kotliarov_rv@mail.ru

Accepted in revised form December 26, 2017;

Published December 30, 2017

\begin{abstract}
One of the main tasks solved in the development of automatic control systems is the identification of the control object, which consists in obtaining its mathematical description. The nature and type of the mathematical model is determined by the goals and tasks for which it will be used. In the present case, the aim of obtaining the model is the synthesis of an automatic control system. Proceeding from the requirements of control problems, the identification problem consists in determining the structure and parameters of the mathematical model that ensure the best similarity of the model and object responses to the same input action. The article considers the experimental method of obtaining a mathematical description of the control object based on the results of measuring its input and output parameters and then processing the obtained results. The control object is the EP10 emulator made by the Oven Company, which is a miniature furnace. The emulator is used in experimental research in the process of commissioning using thermostat controls, and also applicable for educational purposes as part of training and research stands. As a result of structural identification with subsequent adjustment of the coefficients with the help of parametric identification, a model of the control object in the form of a second order aperiodic link is obtained. Parameters and type of the mathematical model allowed to make calculations and determine the parameters of adjustment of the TRM251 PID-controller. The software implementation of the automatic control system in the MatLAB environment made it possible to evaluate transient processes in a closed system. Thus, the calculation and analysis of the automatic control system in the first approximation were made. The final result can be obtained at the stage of commissioning the automatic temperature control system in the EP10 emulator using adaptation algorithms.
\end{abstract}

Keywords: Structural identification, parametric identification, mathematical model, transfer function

DOI $10.21603 / 2500-1418-2017-2-2-72-78$

\section{INTRODUCTION}

To build an automatic process control system, it is necessary to know its general properties as a control object, from which the control conditions are determined. These properties are determined on the basis of the development of a mathematical model [10, 12]. The control object is characterized by certain properties. The relationship between the steady-state input and output values of the object is determined by the static characteristics. By their form, the control object is classified as linear or non-linear. The time behavior of an object with a change in the input action is described by the dynamic characteristics. Most real objects are characterized by a delay time [7].

The automatic control theory along with methods of synthesis of systems includes methods of identification and assessment of the process state. In practice, the solution of the identification problem with an accuracy sufficient to synthesize an effective automatic control system is a complex procedure, its implementation is carried out using expert decisions taken by the experimenter. To obtain an approximate solution, by which the automatic control system can be calculated in the first approximation, the engineering practice uses methods considered in this article.

The choice of the identification method depends on the self-tuning property of the control object. The output signal of a control object having the self-tuning property asymptotically increases or decreases to a new level with a step change in the signal at its input. For objects that do not have the self-tuning property, the action of the step signal at its input results in a linear increase in the output signal. Objects with self-tuning are called static; objects without self-tuning or with zero self-tuning are called astatic. Electric furnaces represent a classic control object with self-tuning.

Electric resistance furnaces are widely applicable for heat treatment of products in various industries: metallurgy, power engineering, metalworking, ceramics, glass industry, etc. The use of an automatic control system for heat treatment makes it possible to improve the quality of products and to facilitate the work of operating personnel [6]. The use of modern automation technologies and new methods of automatic control significantly reduces the cost of repair and maintenance of process equipment, contributes to the economic benefit due to the rational use of energy resources due to the optimal process control.

The purpose of this article is to describe the application of structural and parametric identification methods in the study of the EP10 furnace emulator as part of the training and laboratory stand and use the results obtained to calculate the controller parameters.

\section{MATERIALS AND METHODS}

The training and laboratory stand on the basis of the EP10 furnace emulator and the TRM251 single-channel

Please cite this article in press as: Pachkin S.G. and Kotlyarov R.V. Implementation of the methods of identification of static control objects. Science Evolution, 2017, vol. 2, no. 2, pp. 72-78. DOI: 10.21603/2500-1418-2017-2-2-72-78.

Copyright (C) 2017, Pachkin et al. This is an open access article distributed under the terms of the Creative Commons Attribution 4.0 International License (http:// creativecommons.org/licenses/by/4.0/), allowing third parties to copy and redistribute the material in any medium or format and to remix, transform, and build upon the material for any purpose, even commercially, provided the original work is properly cited and states its license. This article is published with open access at http:// scienceevolution.ru/. 
programmable PID controller from the OVEN company was created at the Department of Automation of Production Processes and Automated Control Systems. The emulator is a miniature furnace, which is heated by the heat released by the resistance when electric current passes through it. The heater power does not exceed $10 \mathrm{~W}$. Temperature is measured by a built-in resistance temperature detector (RTD) with a graduation of Cu50. The emulator has a convenient case with a transparent cover and is used for experimental research in the process of commissioning using thermostat controls, and also applicable for educational purposes as part of training and research stands.

TRM251 PID controller has two universal inputs, to which the most common types of sensors are connected, including RTD. In normal mode, the controller performs single-channel control according to the indications of the main sensor. If the main sensor fails, the backup sensor is automatically turned on. The controller allows to control the object with high accuracy, thanks to PID control. The instrument gives the output power value, aimed at reducing the deviation of the current value of the controlled value from the setpoint. In the PID controller, the principal point is a smooth change in the heater power. However, considering that most of the real objects (furnaces, boilers, presses) have a high thermal inertia, it can be said not about the mathematically smooth change in the heater power, but about the change in the average power. Therefore, to control the temperature, the instrument generates a PWM signal on two discrete outputs, which is fed to the heater (resistor). In this case, the power of the heater varies from 0 to $100 \%$ due to a change in the duration of its activation [6]. The TRM251 also implements the PID auto-tuning function.

The methods of automatic control theory make it possible to describe the object of research in the simplest case in the form of a one-dimensional object whose input is acted upon by a variable characterizing a control parameter, and at the output - by a variable characterizing some indicator of the process. The problem of identifying such an object for the purpose of constructing automatic control systems is to determine the characteristics in the form of adequate mathematical models in the operating range.

Modern identification methods use a combination of analytical and experimental methods. This is due to the fact that a purely analytical approach in many cases does not provide a mathematical model that is sufficiently appropriate to the real control object. Therefore, the combined approach, when the general form of the mathematical description is determined analytically, and the values of the coefficients corresponding to a specific control object are determined experimentally is the most effective $[1,13,17]$.

At the stage of structural identification of the object, we apply an analytical approach, when the choice of the structure of the model is carried out based on the results of the experiment or other a priori information about the object. When solving problems of structural identification, as a rule, linear models of the control object are used in the form of a transfer function. The most frequently chosen model is a model consisting of successively incorporated aperiodic links and a transport delay link. Moreover, sufficient accuracy of solving the identification problem is achieved by using one or two aperiodic links. Thus, the transfer function $W(S)$, reflecting the behavior of the control object, can be written in the form of a transfer function of a first-order aperiodic link with delay (1), a second-order aperiodic link (2) or a second-order aperiodic link with delay (3).

$$
\begin{gathered}
W(S)=\frac{k}{T \cdot S+1} \cdot e^{-\tau \cdot S} \\
W(S)=\frac{k}{\left(T_{3} \cdot S+1\right)\left(T_{4} \cdot S+1\right)}=\frac{k}{T_{2} \cdot S^{2}+T_{1} \cdot S+1} \\
W(S)=\frac{k}{\left(T_{3} \cdot S+1\right)\left(T_{4} \cdot S+1\right)} \cdot e^{-\tau \cdot S}= \\
=\frac{k}{T_{2} \cdot S^{2}+T_{1} \cdot S+1} \cdot e^{-\tau \cdot S}
\end{gathered}
$$

where $k$ is a gain; $T, T_{1}, T_{2}, T_{3}, T_{4}$ are time constants; $\tau$ is a delay time; $S$ is the Laplace variable.

At the stage of parametric identification in engineering practice, a time method got widespread use, which reduces to the experimental determination of the transfer characteristic or the transient response curve. At the beginning of the experiment, the object is brought to a steady state. After this, the input value is step-like changed by $10-15 \%$ of the maximum permissible input value. The experiment is considered complete when the output value reaches a new steady state value for objects with self-tuning. During the experiment, special attention is paid to the synchronization of registrations of the input and output values. The resulting curve is processed by the "tangential method", which makes it possible to determine the transfer function parameters.

The problem of parametric identification of a control object is to determine the parameters of its mathematical model, which ensure the greatest similarity of the reactions of the model and the object to the same input action.

To do this, we first need to derive equations for the dependence of the output signal on the input signal, called in the control theory practice $[11,15]$ the step response $h(t)$, which have the form for a first-order aperiodic link with delay (4), for a second-order aperiodic link (5) and for a second-order aperiodic link with delay (6).

$$
\begin{gathered}
h(t)=k\left(1-e^{-\frac{t-\tau}{T}}\right), \\
h(t)=k\left(1-\frac{T_{3}}{T_{3}-T_{4}} e^{-t / T_{3}}+\frac{T_{4}}{T_{3}-T_{4}} e^{-t / T_{4}}\right), \\
h(t)=k\left(1-\frac{T_{3}}{T_{3}-T_{4}} e^{-\frac{t-\tau}{T_{3}}}+\frac{T_{4}}{T_{3}-T_{4}} e^{-\frac{t-\tau}{T_{4}}}\right)
\end{gathered}
$$

The simplest similarity criterion $q$ is the modular criterion (7):

$$
q=|y(t)-Y(t)|
$$

where $y(t)$ - experimental value of the output variable of the control object; $Y(t)$ - value of the output variable of the control object model. 
Since the experiment results are most often represented as an array, the following similarity criterion notation is used:

$$
q=\sum_{i=1}^{n}\left|y_{i}(t)-Y_{i}(t)\right|
$$

where $y_{i}(t)$ - experimental value of the output variable of the control object in the $i$-th point; $Y_{i}(t)$ - value of the output variable of the control object model in the $i$-th point; $n$-dimension of the experimental data array.

With a normal distribution of the random error of the experiment, the use of the quadratic criterion gives the greatest accuracy:

$$
q=(y(t)-Y(t))^{2}=\sum_{i=1}^{n}\left(y_{i}(t)-Y_{i}(t)\right)^{2}
$$

If it is necessary to highlight the significance of some points in the array of experimental results, a weighted criterion is used:

$$
q=\sum_{i=1}^{n} d_{i} \cdot\left(y_{i}(t)-Y_{i}(t)\right)^{2},
$$

where $d_{i}$ - weighting factor, determining "weight" of the $i$-th point.

In order to intercompare these similarity criteria, it is necessary to rewrite them in a relative form:

$$
\delta=\sqrt{\frac{\left(\frac{\left.\sum_{i=1}^{n}\left(y_{i}(t)-Y_{i}(t)\right)^{2}\right)}{y_{u s t}}\right)}{n+1}} \cdot 100 \%,
$$

where $y_{\text {ust }}$ - steady-state value of the output variable with $t \rightarrow \infty$ (for the normalized values $y_{u s t}=1$ ).

The target values of the parameters of a model of the object described by a first-order aperiodic link with delay are the delay time $\tau$ and the time constant $T$. For a model described by a second order aperiodic link these values are the time constants $T_{3}$ and $T_{4}$ (or $T_{1}$ and $T_{2}$ ). For a model described by a second order aperiodic link with delay these values are the time constants $T_{3}$ and $T_{4}$ (or $T_{1}$ and $T_{2}$ ) and the delay time $\tau$. The transfer coefficient $k$ in static objects does not require adjustment, it is calculated in advance with $t \rightarrow \infty$.

The target values are determined by minimizing the similarity criterion. This minimum should be close to zero, and ideally it is zero. I.e. the problem of parametric identification is optimization, in which the criterion of optimality is the similarity criterion of the control object and its mathematical model.

To adjust the parameters of the control object model, several methods can be identified [2,9]. Among them, various scanning methods and some gradient methods are used most often. Since the initial values of the parameters cannot be precisely determined, it is desirable to use "rough" methods in the first stage of parametric identification, but with a large range of values for the parameters of the control object model. The scanning method with constant step is the best suitable for this purpose. The scanning method is in no way connected with the presence of local optima of the objective function.
Adjustment of the obtained values can be done either by scanning with decreasing step, or by one of the gradient methods.

The general disadvantage of gradient methods in optimization is that they all "get stuck" in the nearest local optimum, in the region of attraction of which the chosen initial point of descent falls. The second and more significant disadvantage in this case is that they are applicable only to "smooth" functions. The use of the gradient method showed that it cannot be used to find the optimal value of the similarity criterion. This is due to the fact that it cannot be attributed to "smooth" functions. Theoretical data are compared with an arbitrary set of experimental data, which does not give a smooth connection of its closest values.

In this regard, the best option as an adjustment is the use of the scanning method with decreasing step.

The main advantage of the scanning method is that when using it with a sufficiently "dense" arrangement of the points being examined, finding of a global optimum is always guaranteed, since the entire range of variation of the independent variables is analyzed. Another advantage is the independence of search from the type of optimized function.

The disadvantage of the method is, first of all, the need to calculate the values of the target function for a larger number of points. This should ensure that the optimum will not be missed when applying this search method.

The simplest algorithm for searching for an optimum is the scanning method, sometimes called the search over a grid of variables, is that increments are given for each independent variable in the appropriate order, ensuring that the entire region of variation of these variables is filled with a uniform and sufficiently dense grid. In the simplest case of two variables $x_{1}$ and $x_{2}$, scanning is reduced to viewing the optimality criterion values with a given value of one variable $x_{2}$ for a number of values of the other $\mathrm{x}_{1}$, which are defined as spaced apart by the step size $\Delta x_{1}$ for the variable $x_{1}$. After the whole range of variation of the variable $x_{1}$ for a given value of $x_{2}$ is investigated and the minimum value of the optimality criterion is found for it, the value of the variable $x_{2}$ also is changed by the amount of some step $\Delta x_{2}$ for this variable and so on. A graphical representation of the scanning search for two variables is shown in Fig. 1.

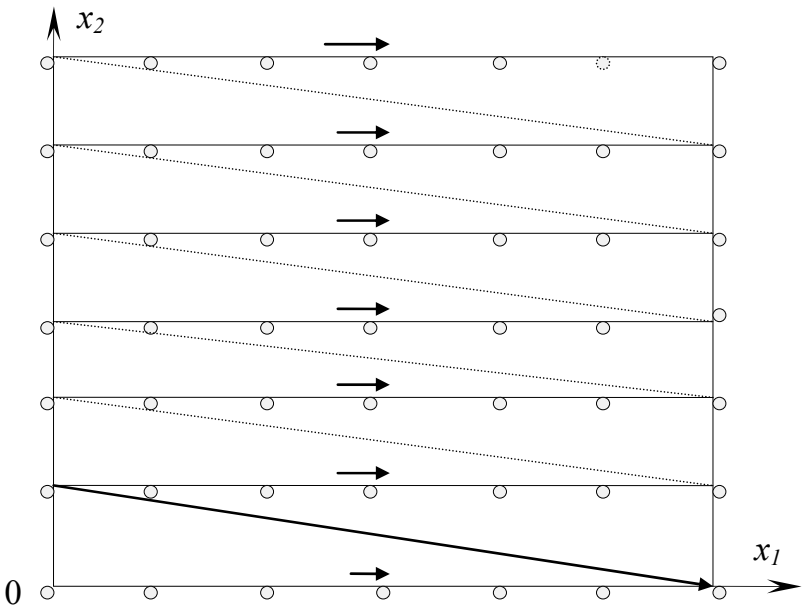

Fig. 1. Search pattern in the scan method. 
For an arbitrary number of independent variables, the step for each next variable is performed after the cycle for the previous one is completed.

Additional restrictions on independent variables essentially do not complicate the procedures for using the scanning method, since in this case the points that do not satisfy the given conditions are simply excluded from consideration and the value of the optimality criterion in them is not calculated. The presence of additional constraints on independent variables even speeds up the solution of the problem if, of course, these constraints are not specified in the form of difficult computations, since the possible range of variation is narrowed and the optimality criteria are calculated with a smaller number of points.

It is not difficult to obtain an estimate of the computational costs when applying the scanning method. So, in case of finding the optimum of the target function under the condition that the accuracy of determining the position of this optimum is $\Delta$, that is, the target values of the normalized variables should not differ from the true position of the optimum by an amount greater than $\Delta$, the number of calculated values of the target function will be

$$
S=\left(\frac{1}{\Delta}\right)^{n},
$$

where $n$ is the number of independent variables of the problem being solved (the dimension of the problem).

To find the optimum of a function of two variables $(n=2)$ with an accuracy of $\Delta=10^{-3}$ using formula (12), we find:

$$
S=\left(\frac{1}{10^{-3}}\right)^{2}=10^{6}
$$

To find the optimum of a function of three variables $(n=3)$ with the same accuracy, we obtain:

$$
S=\left(\frac{1}{10^{-3}}\right)^{3}=10^{9}
$$

Thus, the number of calculations of the optimality criterion in determining the position of the optimum of the scanning method increases in the exponential dependence on the dimension of the problem being solved. Therefore, the effective application of this method is mainly limited to problems of low dimensionality $n=2 \div 3$, if the simplest search algorithm, considered above, is used to find the optimum with low accuracy.

There are various modifications of the scanning method, used mainly to reduce the amount of calculations. One of such modifications is the use of an algorithm with a variable scan step. Initially, the step size is chosen to be sufficiently large, possibly much greater than the required accuracy of determining the position of the optimum, and a rough search is performed that localizes the region of the global optimum. After the area is defined, a search with a smaller step is performed only within the specified area. In practice, it is possible to organize a whole series of such procedures of successive adjustment of the optimum. After the area is defined, a search with a smaller step is performed only within the specified area. In practice, it is possible to organize a whole series of such procedures of successive adjustment of the optimum. The required volume of calculation of $S$ values of the target function is substantially reduced and can be calculated by the formula:

$$
S=k^{-r \cdot n}\left(\frac{1}{\Delta}\right)^{n}+r(2 k)^{n}
$$

where $n$ - the problem dimension; $\Delta$ - accuracy of optimum determination; $r-$ number of search adjustment steps on which the search step is reduced by $k$ times.

The initial step of the grid of variables $\Delta_{0}$ in this case is determined by the formula:

$$
\Delta_{0}=k^{-r} \cdot \Delta
$$

For example, when searching for an optimum of a function of two variables $(n=2)$ with accuracy $\Delta=10^{-3}$, using two stages of step size adjustment $(r=2)$ in $k=10$ times, that is, with initial step $\Delta_{0}=0,1$, the required amount of calculations is:

$$
S=k^{-2 \cdot 2}\left(\frac{1}{10^{-3}}\right)^{2}+2(2 \cdot 10)^{2}=900
$$

This reduces the amount of calculations by more than 1000 times compared to scanning with a constant step. For a function of three variables $(n=3)$, respectively, it is possible to find:

$$
S=k^{-2 \cdot 3}\left(\frac{1}{10^{-3}}\right)^{3}+2(2 \cdot 10)^{3}=1700
$$

That is, the gain in comparison with the application of a constant step is even more significant.

Fig. 2 shows a variable-step search for a function of two variables. The circle indicates the true position of the optimum, and the cross indicates the approximation, found as a result of rough search.

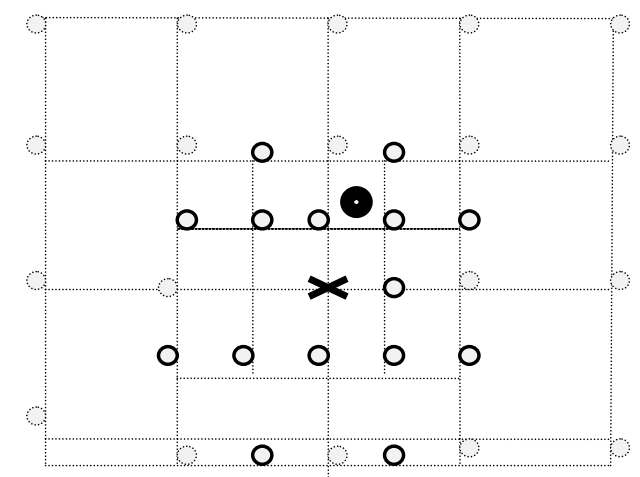

Fig. 2. Search pattern in the variable-step scan method.

The most important point when using the variablestep scanning method is to select the initial rough search step. If the initial step size is chosen too large, there may be a risk of missing the global optimum. If the initial step is chosen too small, the amount of calculations 
required for the search may be large. When choosing the size of the initial step, information about the behavior of the target function, the presence of local extremums, etc. can be of considerable help.

Along with the choice of the initial step of scanning is the task of determining the search boundary for each of the variables. The correctness of the choice of the boundary depends on the accuracy of the input of the initial values of the unknown variables. This problem is solved in two stages. At the beginning, the left boundary is approximately determined by 10 -fold decreasing the initial value, and the right boundary is approximately determined by 10 -fold increasing the same initial value. In the future, if at the first scan with a constant step the desired point appears on some boundary, then before using the method of scanning with variable step, the boundary is increased (or decreased) two times and the scan is repeated in the indicated direction. This procedure is repeated until the minimum of the similarity criterion is located on any boundary.

\section{RESULTS AND DISCUSSION}

As a result of the analysis of the EP10 emulator, its structural diagram as a one-dimensional control object is formed (Fig. 3).

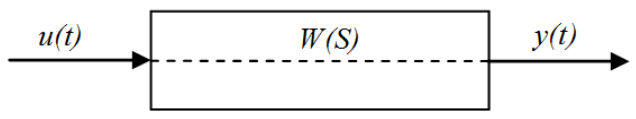

Fig. 3. Structural diagram of a one-dimensional control object.

The power (\%) output by the TRM251 PID controller is selected as the input control action $u(t)$. The output parameter $y(t)$ is the air temperature in the "furnace" $\left({ }^{\circ} \mathrm{C}\right)$.

In order to obtain the transient response characteristic, an experiment was carried out. The control object is brought to the full operating range in the manual mode. Then the output parameter is stabilized at a value of $50{ }^{\circ} \mathrm{C}$, after which a $30 \%$ power action is introduced. The obtained graph of the transient response characteristic was processed by the "tangential method", which allowed obtaining the parameters of the transfer functions (1), (2) and (3).

The parameters of the transfer functions were refined with the help of a software that implements methods for the numerical solution of the optimization problem. The adjustment results are presented in Tables 1, 2 and 3.

When the transient response characteristic of the control object is approximated, the best result is provided by the quadratic criterion - in the case of an aperiodic link of the first order, and a weighted criterion - in the case of an aperiodic link of the second order. The analysis of the results of parametric identification (Tables 2 and 3) allows to say that there is no delay when the control object is approximated by a secondorder aperiodic link. Therefore, the transfer functions (1) and (2) are chosen as the basic mathematical models. The transient response curves of the control object described by a first-order and a second-order aperiodic links with delay are shown in Fig. 4.
Table 1. Parameters of the transfer function of the control object in the form of a first-order aperiodic link with delay (1)

\begin{tabular}{|c|c|c|c|}
\hline \multirow{2}{*}{$\begin{array}{c}\text { Transfer function } \\
\text { parameter }\end{array}$} & \multicolumn{3}{|c|}{ Similarity criterion } \\
\cline { 2 - 4 } & modular & quadratic & weighted \\
\hline$k,{ }^{\circ} \mathrm{C} / \%$ & 3.12 & 3.21 & 3.23 \\
\hline$T$, min & 0.75 & 0.63 & 0.63 \\
\hline$\tau$, min & 2.63 & 0.11 & 0.12 \\
\hline $\begin{array}{c}\text { Similarity } \\
\text { criterion value }\end{array}$ & \multicolumn{3}{|c|}{} \\
\hline
\end{tabular}

Table 2. Parameters of the transfer function of the control object in the form of a second-order aperiodic link (1)

\begin{tabular}{|c|c|c|c|}
\hline \multirow{2}{*}{$\begin{array}{c}\text { Transfer } \\
\text { function } \\
\text { parameter }\end{array}$} & \multicolumn{3}{|c|}{ Similarity criterion } \\
\cline { 2 - 4 } & modular & quadratic & weighted \\
\hline$k,{ }^{\circ} \mathrm{C} / \%$ & 3.84 & 3.76 & 4.12 \\
\hline$T_{1}, \min$ & 1.82 & 1.96 & 0.99 \\
\hline$T_{2}, \min$ & 3.29 & 3.13 & 0.26 \\
\hline$T_{3}, \min$ & 0.55 & 0.63 & 3.86 \\
\hline$T_{4}, \min$ & 1.89 & 0.07 & 0.01 \\
\hline $\begin{array}{c}\text { Similarity } \\
\text { criterion value }\end{array}$ & & & \\
\hline
\end{tabular}

Table 3. Parameters of the transfer function of the control object in the form of a second-order aperiodic link with delay (1)

\begin{tabular}{|c|c|c|c|}
\hline \multirow{2}{*}{$\begin{array}{c}\text { Transfer } \\
\text { function } \\
\text { parameter }\end{array}$} & \multicolumn{3}{|c|}{ Similarity criterion } \\
\cline { 2 - 4 }$k,{ }^{\circ} \mathrm{C} / \%$ & modular & quadratic & weighted \\
\hline$T_{1}, \min$ & 3.83 & 3.80 & 4.08 \\
\hline$T_{2}, \min$ & 1.88 & 1.90 & 0.88 \\
\hline$T_{3}, \min$ & 3.25 & 3.20 & 0.23 \\
\hline$T_{4}, \min$ & 0.58 & 0.60 & 3.85 \\
\hline$\tau$, min & 0 & 0 & 0.03 \\
\hline $\begin{array}{c}\text { Similarity } \\
\text { criterion value }\end{array}$ & 1.90 & 0.07 & 0.01 \\
\hline
\end{tabular}

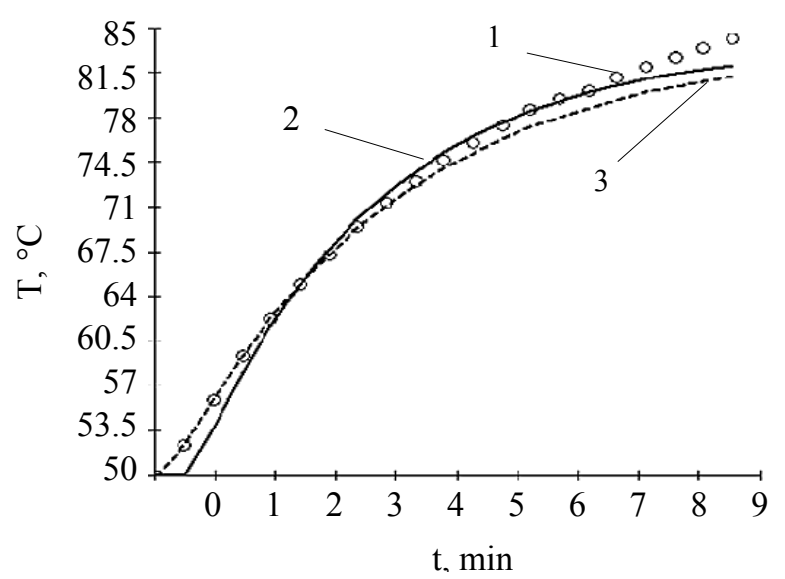

Fig. 4. Results of parametric identification of the control object: 1 - experimental values; 2 - transient response curve of the control object, described by a first-order aperiodic link with delay; 3 - transient response curve of the control object described by a second-order aperiodic link. 
The first-order model gives a too rough approximation to the object under consideration. On the transient response curve, there is a zone of pure delay, which is not characteristic for small control objects, especially in the training and research stand, since the output parameter begins to change almost immediately after the start of the action of the input variable.

A second-order model describes the control object more accurately. There is no pure delay zone. The total delay is determined only by a capacitive delay, which is more typical for a real object. In this case, the transient response curve accurately approximates the initial section of the experimental data.

The transfer function (19) is selected as the basic mathematical model of the EP10 furnace emulator.

$$
\begin{aligned}
W(S) & =\frac{1.15}{(0.26 \cdot S+1)(3.86 \cdot S+1)}= \\
& =\frac{1.15}{0.99 \cdot S^{2}+4.12 \cdot S+1}
\end{aligned}
$$

The properties of the control object are determined by the results of its identification [7, 8]. Proceeding from the obtained transfer function, we can say that the object has the property of self-tuning. However, it is affected by environmental disturbances. At the same time, the stabilization of the output parameter can take a considerable time, for which, although it stabilizes, it can reach an unacceptable value. In this case, for the optimal flow of the process, the required parameter should be adjusted.

Identification of the control object is the initial step in the design of the automatic control system [4, 14]. In particular, the problem of choosing the control law is solved based on the ratio of the delay time $\tau$ to the time constant of the object $T$ (20) in accordance with the values of Table. 1

$$
\frac{\tau}{T}=\frac{0.63}{3.21}=0.2
$$

For ratios $\geq 0.2$, it is advisable to select a continuous controller. The settings of the automatic controller can be determined on the bases of parameters of the transfer function of the control object $[2,5,16]$. In general, the transfer function of the PID controller is represented by the relationship (21).

$$
\begin{aligned}
& W_{c}(S)=k_{c}+\frac{1}{T_{i} \cdot S}+T_{d} \cdot S= \\
& =k_{c} \cdot\left(1+\frac{1}{T_{i a} \cdot S}+T_{d a} \cdot S\right),
\end{aligned}
$$

where $k_{c}-$ controller gain; $T_{i}-$ integration time; $T_{d}$ - differentiation time; $T_{i a}-$ integral action time; $T_{d a}$ - derivative action time.

Let us use a special software, which involves an approximate calculation of the controller, and calculate the settings of the controller, which provides a stable control process in a closed system. The results of the calculation are given in Table. 4.
Control process charts allow to speak about stability of the automatic control system as a whole. The choice of the controller settings depends on the control quality requirements [3].

Software implementation of the mathematical model of the training and research stand (Figure 5), including the control object model (Transfer Fcn) and the controller model (PID Controller), is performed in the MatLAB environment. The curves temperature control processes of the EP10 emulator are obtained with the help of the TRM251 PID controller (Fig. 6). The curves show the response of the system to the step input action.

Thus, the article reflects the main stages and methods of structural and parametric identification using the example of a real object - the EP10 furnace emulator. Parameters of the TRM251 PID controller, which allow to realize automatic regulation of the furnace temperature, are obtained. The software implementation of mathematical models of the control object and controller makes it possible to evaluate the behavior of a closed automatic control system. The known adaptation algorithms can be helpful to obtain controller settings for controlling a real object.

Table 4. TRM251 PID controller parameters

\begin{tabular}{|c|c|c|c|}
\hline \multirow{2}{*}{$\begin{array}{c}\text { Typical } \\
\text { control law }\end{array}$} & \multicolumn{3}{|c|}{ Controller setting parameters } \\
\cline { 2 - 4 } & $k_{c}, \% /{ }^{\circ} \mathrm{C}$ & $\mathrm{T}_{\mathrm{i} a}, \min$ & $\mathrm{T}_{\mathrm{da}}, \min$ \\
\hline PI-law & 9.004 & 1.088 & - \\
\hline PID-law & 28.510 & 0.492 & 0.123 \\
\hline
\end{tabular}

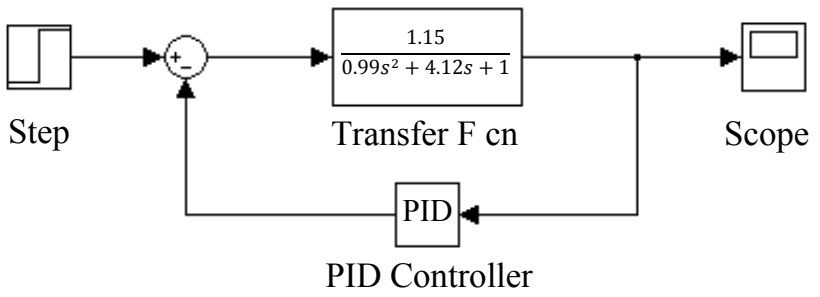

Fig. 5. Software implementation of the mathematical model in the MatLAB environment: Step - block of step input action; Transfer Fcn is a second- order aperiodic link; PID Controller - PID controller; Scope - the chart field.

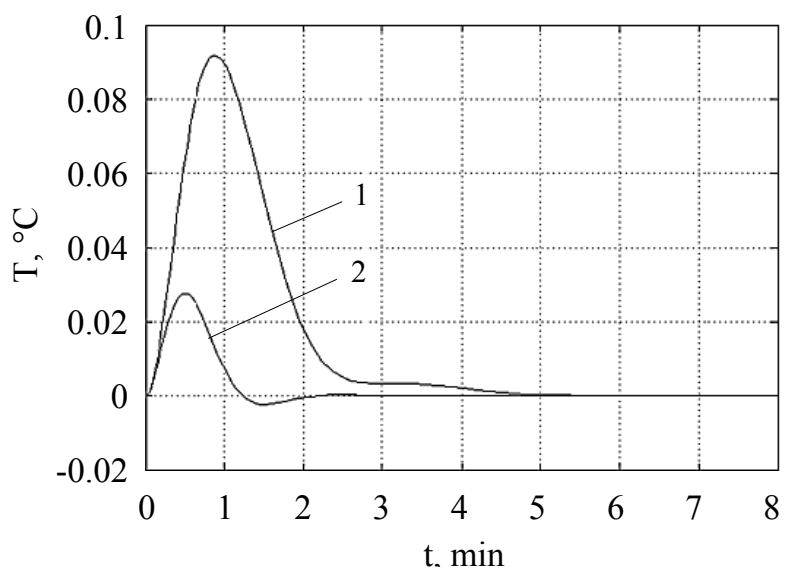

Fig.6. Temperature control process charts: 1 - PI control law; 2 - PID control law. 


\section{REFERENCES}

1. Genov A.A., Rusakov K.D., and Hill S.S. Identifikatsiya sostoyaniya slozhnoy tekhnicheskoy sistemy v usloviyakh neopredelennosti izmeritel'noy informatsii [Identification of a Complex Technical System Functional State under Conditions of Measurement Data Ambiguity]. Programmnyye produkty i sistemy [Software \& Systems], 2017, no. 3, pp. 373-377.

2. Zakharova O.V. Novyy metod formirovaniya upravlyayushchikh vozdekstviy dlya PID regulyatora [New Method of Formation of Control Actions for PID Controller]. Sovremennye naukoemkiye tekhnologii [Modern High Technologies], 2015, no. 12-4, pp. 595-600.

3. Zver'kov V.P. and Petrochenko Yu.N. Sistemy avtomaticheskogo upravleniya dinamicheskimi ob'ektami s PID-regulyatorom v rezhime normal'noy ekspluatatsii [Dynamic Objects Automatic Control Systems with PID-regulator at Normal Operation Mode]. Novoe v rossiyskoy elektroenergetike [New in the Russian Power Industry], 2017, no. 4, pp. 25-36.

4. Makarova N.V., Nemchinova E.A., and Pyreseva O.S. Analiz raboty sistemy avtomaticheskogo upravleniya s PID-regulyatorom [Analysis of the Automatic Control System with PID Controller]. APRIORI. Estestvennyye $i$ tekhnicheskiye nauki [APRIORI. Natural and Technical Sciences], 2016, no. 6, p. 20.

5. Mezhakov O.G. and Sklyarov A.A. PID-regulyator ponizhayushchego preobrazovatelya napryazheniya [PID-regulator of the Lowering Voltage Converter]. Molodoy uchenyy [Young Scientist], 2015, no. 10(90), pp. 257-261.

6. Fedonin O.N., Handozhko V.A., and Matlakhov V.P. Sistema avtomaticheskogo upravleniya temperaturoy v trekhzonnoy pechy s mikroprocessornym PID-regulyatorom firmy «OWEN» [Automatic Three-zone Temperature Control Furnace Microprocessor PID Controller Company «OWEN»]. Vestnik Bryanskogo gosudarstvennogo tekhnicheskogo universiteta [Bulletin of Bryansk State Technical University], 2015, no. 3, pp. 98-104.

7. Khudyakova L.A., Shovgenyuk Yu.V., Stashkevich V.F., and Kulakhmetov D.R. Nastroyka parametrov PID-zakona v regulyatorakh temperatury [PID Temperature Regulator Parameters Adjustment]. Vestnik Natsional'nogo tekhnichnogo universiteta Ukrainy "Kievskiy politekhnicheskiy institut" [Bulletin of the National Technical University of Ukraine "Kiev Polytechnical Institute"], 2016, no. 51(1), pp. 81-88.

8. Aslam S., Hannan S., and Zafar W. Temperature Control of Water-bath System in Presence of Constraints by Using MPC. International Journal of Advanced and Applied Sciences, 2016, no. 12, pp. 62-68.

9. Lees M. and Wang L. PID controller design for industrial beer filtration. 5th Australian Control Conference (AUCC), 2015 , pp. 306-311.

10. Lobasenko B.A. and Semenov A.G. Intensification of ultrafiltration concentrating by the separation of the concentration boundary layer. Food and Raw Materials, 2013, no. 1, pp. 74-81.

11. Nie Z.Y., Wang Q.G., Liu R.J., and Lan Y.H. Identification and PID Control for a Class of Delay Fractional-order Systems. IEEECAA Journal of Automatica Sinica, 2016, no. 4, pp. 463-476.

12. Osintsev A.M., Gromov E.S., and Braginsky V.I. A phenomenological model of milk coagulation. Food and Raw Materials, 2013, no. 1, pp. 11-18.

13. Patrascu M. and Ion A. Evolutionary Modeling of Industrial Plants and Design of PID Controllers Case Studies and Practical Applications. Nature-inspired computing for control systems, 2016, vol. 40, pp. 73-119.

14. Prabhu P.S., Prathipa R., and Shanmugasundaram B. Design and development of two degree of freedom model with PID controller for turning operation. Journal of measurements in engineering, 2016, no. 4, pp. 224-231.

15. Prokop R., Korbel J., and Matusu R. Algebraic methods in autotuning design: implementation and simulations. 4th Computer Science On-line Conference (CSOC), 2015, vol. 348, pp. 79-89.

16. Yu E. and $\mathrm{Hu}$ Y. A novel modified PID controller applied to temperature control with self-tuning ability. Proceedings of the 28th Chinese control and decision conference, 2016, pp. 7025-7029.

17. Zhang X.X. and Xu J. Identification of time delay in nonlinear systems with delayed feedback control. Journal of the Franklin institute-engineering and applied mathematics, 2015, no. 8, pp. 2987-2998.

\section{Sergey G. Pachkin}

Cand.Sci.(Eng.), Associate Professor of the Department of Automation of Manufacturing Processes and Computer-Aided

Control Systems, Kemerovo Institute of Food Science and Technology (University), Kemerovo, Russian Federation

\section{Roman V. Kotlyarov}

Cand.Sci.(Eng.), Head of the Department of Automation of Manufacturing Processes and Computer-Aided Control Systems, Kemerovo Institute of Food Science and Technology (University), Kemerovo, Russian Federation 